\title{
SOBRE MEUS LÁBIOS: VISIBILIDADE E CONTROLE NO FUTEBOL CONTEMPORÂNEO*
}

\author{
Renato Machado Saldanha**
}

\section{RESUMO}

Este artigo busca analisar como o advento da televisão, e sua permanente evolução, provocou (e ainda provoca) grandes alterações no futebol. Apoiado na comparação entre alguns episódios, procuramos refletir sobre como a crescente visibilidade vem alterando, nesses últimos 50 anos, não só a forma de acompanhar esse espetáculo, mas também a sua própria dinâmica.

PALAVRAS-CHAVE: futebol - panoptismo - sociedade de controle

\section{INTRODUÇÃO}

A final da Copa do Mundo de 2006, realizada na Alemanha, não tricampeã mundial e embalada depois de uma grande vitória na semifinal sobre os donos da casa. Do outro, a França, que já havia derrotado a favorita seleção brasileira nas quartas-de-finais, e queria o bi-campeonato para mostrar que o título de 98 não tinha sido um simples golpe de sorte, tampouco obra de um nebuloso esquema de manipulação de resultados. ${ }^{1}$

Se não bastasse isso, o jogo seria o último da carreira de um dos maiores jogadores da história recente do futebol mundial. Aos 34 anos, o craque francês Zinédine Zidane, eleito três vezes o melhor atleta da

* Esse estudo foi realizado como trabalho de conclusão no curso de especialização em Pedagogias do Corpo e da Saúde, da UFRGS, sob a orientação da $\operatorname{Prof}^{a} \operatorname{Dr}^{a}$ Silvana Vilodre Goellner.

** Especialista em Pedagogias do Corpo e da Saúde pela UFRGS, licenciado e bacherel em Educação Física pela UFV. 
temporada pela FIFA² $(1998,2000$ e 2003), anunciava que se despediria do futebol após a Copa.

Apesar de todos esses ingredientes, a imagem desta partida que ficará eternizada na memória dos torcedores não será de nenhum lance genial, ou os dois gols marcados durante o tempo normal, nem mesmo o pênalti desperdiçado por Trézéguet (que valeu o tetra campeonato mundial à Itália). Com exceção talvez dos italianos, os aficionados por esse esporte do mundo inteiro lembrarão desta partida pela reação de Zidane a uma provocação do zagueiro italiano Marco Materazzi.

Aos três minutos do segundo tempo da prorrogação, Zidane saía da área italiana. Caminhava em direção ao meio do campo e, a cada passada, discutia com o zagueiro Marco Materazzi. O capitão da França já estava uns três metros à frente, quando Materazzi disse algo que o enfureceu. Zidane virou-se em direção ao italiano, avançou até ele, destemperado como um juvenil, e o atingiu com uma violenta cabeçada no meio do peito. Materazzi caiu, o árbitro argentino Horacio Elizondo consultou o auxiliar e expulsou o jogador francês (ZERO HORA, 2006, p. 5).

A partir daí, a pauta de todos os jornais esportivos nas próximas semanas já estava definida. $\mathrm{O}$ assunto da vez não seria a decisão por pênaltis, nem o equilíbrio da partida, muito menos o estilo de jogo dos finalistas. Todo o contexto do jogo em Berlim foi reduzido à polêmica sobre o insulto de Materazzi e a resposta de Zidane.

Apesar de o fato ter monopolizado as atenções da mídia por vários dias, a atitude do jogador francês está longe de ser um caso inédito no futebol. Não é preciso vasculhar muito o passado desse esporte, para perceber que brigas e confusões entre atletas não são nada incomuns. A própria equipe brasileira bicampeã do mundo em 58 e 62, considerada por muitos como ícone de um futebol bem jogado (ou futebol-arte), esteve envolvida em uma autêntica guerra contra os uruguaios, durante uma partida válida pelo Campeonato Sul-Americano de 59, na Argentina.

O jogo foi esquentando... Esquentando... E, de repente, como que comandados por uma voz geral, sem que fosse possível prever tão antecipado o desfecho esperado, os vinte e dois jogadores, os reservas, diretores, fotógrafos, enfim, todos puseram-se a travar verdadeira batalha campal. 
Nós que estivemos dentro do gramado, assistimos de perto a cenas verdadeiramente assombrosas. Paulo Valentim e Chinezinho, pegaram ao centro médio Gonçalves a um costado da cancha e o deitaram por terra a socos e pontapés. Almir, mau grado seu tamanho, atirou-se como um leão contra William Martinez e, ajudado por Marco Américo, chutoulhe a cara e a cabeça por diversas vezes. Paulo Amaral, o atlético preparador físico brasileiro, dava saltos de quase metro e meio e desferia os dois pés justos no peito dos uruguaios mais próximos, deitando-os invariavelmente no solo. Parecia, para nós, que haviam mais de dois brasileiros (argentinos inclusive) para cada uruguaio. Houvesse demorado um pouco mais a briga e teríamos tido uma verdadeira chacina. É claro que, depois de tanto dar, também tivéssemos sofrido algumas baixas. Orlando e Castilho foram os atingidos mais seriamente mas foi insignificante em relação ao que apanharam os "valientes" uruguaios. [...]

Quando tudo parecia que ia terminar bem, quando a vitória brasileira não admitia contestação e quando alguns jogadores trocavam abraços pelo final da partida, o meia esquerda Sasia houve por bem (ou por mal) desferir um violento pontapé em Bellini. Foi a conta. Nova sessão de luta livre, com novo "round" favorável ao Brasil, que esteve ontem absoluto no Estádio do River Plate: ganhou em futebol por 3 a 1 e em luta por dois rounds a zero, com elevado saldo favorável de pontos (DIÁRIO DE NOTÍCIAS, 1959, p. 12).

Quarenta e sete anos separam os dois episódios. Entre eles, a diferença é ínfima e total. Ínfima se pensarmos que a disposição dos jogadores de futebol para trocar a disputa pela bola por sessões de "sopapos" e cabeçadas continua a mesma. Total se considerarmos que, nesse quase meio século, esse esporte passou por várias mutações (das mais diferentes ordens e pelas mais variadas razões). A forma como os meios de comunicação da época repercutiram os dois episódios, nos ajuda a pensar em algumas destas mudanças:

a) Zidane, quem diria, mete a cabeça no peito de Materazzi e é correta, dramática e melancolicamente expulso de campo, último ato incompreensível de um gênio da bola, por mais que sempre tenha sido um pouco instável. [...] Ah, Zidane. Que merde! Ele deixou seus companheiros ao deus dará. Nem para bater mais um pênalti estaria... Que merde!!! (KFOURI, 2006); 
b) Os jogadores brasileiros conquistaram na noite de ontem uma vitória que está destinada a passar à história do futebol sul-americano. Venceram, com relativa facilidade a peleja e ainda por cima aplicaram tremenda surra aos jogadores uruguaios.

Valeu a pena ver Paulinho Valentin colocar três bolas nas redes de Leivas e, como complemento, os jogadores da camiseta verde amarela desferindo socos e pontapés a torto e a direito "massacrando" pela primeira vez na história do futebol aos leões de chácara do futebol platino (DIÁRIO DE NOTÍCIAS, 1959, p. 3).

A diferença aqui é notória. Enquanto a briga entre brasileiros e uruguaios é festejada pela imprensa local, a atitude de Zidane é lamentada, veementemente reprovada. Mas o que teria levado a essa drástica transformação? A diferença no estilo da narrativa (uma sucinta, mais comentada, outra uma longa descrição) sugere uma diferença fundamental entre os dois períodos: a presença da televisão.

Neste texto, buscarei analisar como o advento da televisão, e sua permanente evolução, provocou (e ainda provoca) grandes alterações dentro do futebol.

\section{A TELEVISÃO ENTRA EM CAMPO}

E o patético é que, quinta-feira, o vídeo-tape de Brasil x Inglaterra nos dera uma versão deprimente do escrete. O povo não sabia como conciliar as duas coisas: - o delírio dos locutores e a exata veracidade da imagem. Após a batalha de ontem, eu vi tudo. A verdade está com a imaginação dos locutores. E repito: - a imaginação está sempre muito mais próxima das essências. Ao passo que o vídeo-tape é uma espécie de lambe-lambe do Passeio Público, que retira das pessoas toda a sua grandeza humana e esvazia os fatos de todo o seu patético.

Disseram os locutores que o Brasil fizera, contra a Inglaterra, uma exibição deslumbrante. Pura imaginação e, por isso mesmo, altamente veraz. O vídeo-tape demonstrou o contrário. Azar da imagem (RODRIGUES, 1993, p. 90).

No trecho acima, retirado de uma crônica sobre um jogo da seleção brasileira na Copa do Mundo do Chile, em 1962, Nelson Rodrigues 
explicita todo o seu descontentamento com uma mudança que estava em curso: uma nova forma de se acompanhar uma partida de futebol.

Até então, assistir a uma partida requeria, obrigatoriamente, a presença no estádio. Ao torcedor distante, só restava acompanhar o jogo pelo rádio, ou esperar que o jornal do dia seguinte trouxesse fotos, relatos e crônicas sobre o evento. Essas duas últimas opções exigiam do torcedor um grande esforço imaginativo para reconstruir mentalmente as jogadas descritas, com grande dose de lirismo e exagero, por locutores e cronistas.

Aos poucos, a televisão começa a ganhar espaço no Brasil ${ }^{3}$, e com ela surgem as primeiras transmissões esportivas ${ }^{4}$ e uma nova relação, mais direta, mais objetiva, do público longínquo com o jogo. Os locutores, que no rádio eram os protagonistas, os intermediários fundamentais entre os ouvintes e o evento ("esses mestres do suspense [que] correm mais que os jogadores e mais que a própria bola, e em ritmo de vertigem narram uma partida que pode não ter muita relação com o que se está olhando"), na televisão se transformam em meros coadjuvantes, que "acompanham as imagens, mas sabem muito bem que não podem competir com elas" (GALEANO, 2004, p. 22). Deixávamos para trás a era da imaginação do jogo ouvido no rádio ou lido nos jornais, para entrar na era da exatidão incontestável da imagem.

Mais do que uma mera atitude ludista, de negação da tecnologia, a resistência de Nelson Rodrigues à objetividade do vídeo-tape parece ser a defesa da fantasia, da polêmica e da imaginação, como elementos fundamentais ao futebol.

O aperfeiçoamento das transmissões foi adicionando novas câmeras que, espalhadas por todo o redor do campo, passaram a permitir ao telespectador uma visibilidade total da partida. Nenhum pormenor passaria mais desapercebido por esses olhos eletrônicos, a ponto de Eduardo Galeano (2004, p. 165) afirmar que, "hoje em dia, o estádio é um gigantesco estúdio de televisão". Assim, se temos poucos registros da briga de 59 - apenas algumas descrições em jornais, fotos e alguns trechos em vídeo (de má qualidade, que não permitem ver muita coisa) - a agressão de Zidane, por sua vez, além de ter sido assistida ao vivo por mais de 1 bilhão de pessoas em todo o mundo, pôde ser dissecada com minúcia, nos mínimos detalhes, em diversos ângulos diferentes. 
A esse novo estádio que nascia, como um espaço de visibilidade total, um campo permanente de vigilância e punição, Florenzano (1998) vai chamar de "estádio-panóptico".

\section{DO ESTÁDIO PANÓPTICO AO CONTEMPORÂNEO}

O Panóptico é o modelo arquitetônico de confinamento criado por Jeremy Bentham, na época das Luzes. Basicamente, se trata de uma construção circular, composta por celas incomunicáveis entre si, mas com grandes janelas para a face interna e externa do círculo, o que permite que as mesmas sejam atravessadas pela luz. No centro desse círculo, uma torre central, disposta de tal forma que dali se possa enxergar tudo o que acontece no interior das celas, sem que a recíproca seja verdadeira.

Desta forma, o sujeito fica exposto permanentemente à vigilância, embora não possa jamais verificar se está ou não sendo observado. $\mathrm{O}$ efeito de poder disso é que "quem está submetido a um campo de visibilidade, e sabe disso, retoma por sua conta as limitações do poder; fá-las funcionar espontaneamente sobre si mesmo; inscreve em si a relação de poder na qual ele desempenha simultaneamente os dois papéis; torna-se o princípio de sua própria sujeição" (FOUCAULT, 1987, p. 179).

Foucault, ao analisar esse projeto arquitetônico (aplicado com sucesso não só em prisões, mas também em fábricas, escolas, hospitais, manicômios e quartéis), vai ver nele mais do que a solução de um problema técnico (de como manter os sujeitos presos ou sob controle), mas um ideal de sociedade que estava sendo forjado: a sociedade disciplinar.

A sociedade disciplinar vai se organizar com base nos espaços fechados, confinamentos que permitiam multiplicar a força de produção, aumentando sua força útil e diminuindo sua resistência política. Da mesma forma, na década de 1960 se iniciará, no Brasil, um movimento pela "maximização" das nossas forças no futebol. Era a modernização.

A modernização do futebol nacional, segundo Florenzano (1998), teria se iniciado após a Copa do Mundo da Inglaterra, em 1966. Neste torneio, a seleção brasileira, que vinha de dois títulos mundiais consecutivos em 58 e 62, não teve uma boa participação. O péssimo desempenho brasileiro, eliminado ainda na primeira fase do torneio depois de duas derrotas em três jogos, vai irromper um novo campo de forças em 
nosso futebol, e exigir uma profunda reestruturação. O até então considerado virtuoso futebol-arte, motivo de orgulho nacional, de repente passou a ser visto por muitos como lento, ineficaz e ultrapassado. Em nome de uma melhor produtividade, a modernidade condenava-se ao individualismo, ao descontrole emocional, à falta de aplicação tática e ao desleixo com a parte física de nosso jogador.

Ao analisar esse processo de modernização do nosso futebol, o autor identifica o surgimento de diversos dispositivos que incidiam diretamente sobre o corpo dos atletas, visando discipliná-lo. A lei do passe, os códigos disciplinares das equipes (as famosas "cartilhas"), o surgimento de novos especialistas do corpo e da alma dos jogadores (psicólogos, preparadores físicos, fisiologistas, entre outros), a militarização do futebol, o papel de tribunal da norma desempenhado pela imprensa, e a nova configuração dos estádios, seriam os mecanismos disciplinares que buscavam a produção de um tipo de jogador mais adequado à nova fase desse esporte, o "jogador-disciplinar". Para este estudo, detenhamo-nos neste último ponto: o estádio no futebol.

A televisão adquiriu tamanha centralidade no espetáculo, que sua influência não alterou apenas o modo como o público distante assistia-o, mas alterou a própria dinâmica do jogo. As inúmeras câmaras distribuídas ao redor do campo, que originalmente tinham a intenção de garantir o deleite do telespectador, logo se transformaram em incansáveis vigias do comportamento dos atletas. O ingresso de um olhar onipresente e onisciente no campo de jogo ampliou o controle sobre os jogadores, modificando suas atitudes e a própria moral do esporte. As semelhanças entre o projeto arquitetônico desenvolvido por Jeremy Bentham, e a nova configuração do estádio de futebol, com sua ininterrupta observação dos corpos, levou Florenzano (1998) a nomeá-lo de "Estádio Panóptico".

Esse modelo talvez tenha atingido seu ápice em meados da década passada. Durante a partida Itália x Espanha, pelas quartas-de-final da Copa do Mundo de 94, o zagueiro italiano Tassotti, acertou uma cotovelada no rosto do espanhol Luis Enrique. A agressão não foi vista pelo árbitro, nem por seus assistentes, mas não escapou das lentes das câmeras de TV. O flagrante em vídeo bastou para que a FIFA punisse o agressor com sete jogos de suspensão. ${ }^{5}$ Essa foi a primeira vez em que a entidade máxima do futebol admitiu o uso da imagem de TV como 
prova legítima nos julgamentos de atitudes consideradas "anti-desportivas" (até então, o jogador só podia ser julgado por algo que o árbitro visse e relatasse na súmula da partida).

Em pouco tempo, punições como essa se tornaram corriqueiras, e o velho ensinamento "Deve-se bater longe da bola. O árbitro, como as câmeras de televisão, tem os olhos cravados na bola" (GALEANO, 2004, p. 173) caía por terra. Confirmando a idéia de Foucault (1987, p. 154), de que "a visibilidade é uma armadilha", a visibilidade total do campo de futebol se voltava contra o jogador, transformando o gramado em um espaço de permanente vigilância e punição.

Entretanto, doze anos depois, a vigilância sobre os corpos parece ter se radicalizado de tal forma, que já não podemos dizer que se trata da mesma coisa. Pelo menos, é isso o que os desdobramentos do episódio entre Zidane e Materazzi, na final da Copa de 2006, parece nos indicar.

A FIFA, desta vez, puniu o francês (multa em cerca de US\$ 6 mil e mais três jogos de suspensão) e também o italiano (dois jogos de suspensão e mais US\$ 4 mil de multa). A controversa punição ao atleta agredido, mesmo que ele não tenha reagido à agressão, se fundamentou na leitura labial do jogador, que mostrou que ele teria ofendido Zidane momentos antes do episódio. ${ }^{6}$

A leitura labial, em si, não é propriamente uma novidade no futebol. Desde os tempos do Canal 100, ${ }^{7}$ closes nos rostos dos jogadores já permitiam ao público ler inaudíveis palavrões, xingamentos e desabafos. Porém, é a primeira vez que esse recurso é utilizado pela entidade máxima do futebol no julgamento de um jogador.

Embora esse ainda seja um caso único no futebol, é interessante observarmos que, durante o mesmo torneio, a principal inovação na cobertura esportiva da Rede Globo de Televisão foi a criação, dentro de sua revista eletrônica dominical, de um quadro chamado "Jogo Falado", no qual três jovens surdos, especialistas em leitura labial, decifravam o que jogadores e técnicos diziam durante as partidas.

Mais do que uma simples coincidência, os dois fatos juntos sugerem uma nova transformação no modo de se acompanhar uma partida, a sistematização de um novo dispositivo de poder. As câmeras de TV, cada vez mais potentes e sofisticadas, já não se contentam mais apenas em registrar cada jogada, cada drible, ou vigiar os gestos e as atitudes 
dos envolvidos. Agora, esses olhos eletrônicos também se ocupam do monitoramento das falas.

A intenção inicial desse novo interesse parece clara: pela exposição da fala, a televisão, ávida por novidades que assegurem sua audiência, pretendia aproximar seu telespectador das emoções, pensamentos e sentimentos daqueles que participam do espetáculo, escancarar a "alma" de jogadores e técnicos. Entretanto, a punição a Materazzi mostra que a busca pela melhor transmissão, para satisfação do telespectador, novamente é acompanhada por uma alteração no controle sobre o jogador.

Se pelo conteúdo da fala podemos desvendar o pensamento do jogador, torna-se possível definir sua punição de acordo não mais com sua atitude, mas com sua intenção em cometê-la. O jogador que comete uma falta violenta depois de ter ameaçado (ou como se diz no jargão do esporte, "jurado") a vítima, pode ter sua pena ampliada, com a justificativa de que foi um ato premeditado. Da mesma forma, aquele que mostrar que a provocação partiu do outro, poderá ter sua pena atenuada, ou pelo menos conseguir uma punição também para o adversário. Se a máxima: "O fim justifica os meios, e qualquer sacanagem é boa, embora convenha executá-la dissimuladamente" (GALEANO, 2004, p. 173) continua sendo verdade, por outro lado é cada vez mais difícil disfarçar as intenções.

As emoções do jogador também passam a ser monitoradas. Florenzano (1998) já alertava para o surgimento dos "especialistas da alma" como uma exigência do futebol moderno, que incentivava o jogador a responder sempre de forma viril, até mesmo violenta, em momentos de tensão, porém, sem jamais perder o controle. A função desses profissionais, geralmente psicólogos ou o próprio técnico da equipe, era garantir que o jogador estivesse sempre motivado, concentrado, obediente às ordens do seu comandante e equilibrado emocionalmente.

Com o acompanhamento da fala, esse controle, que antes era trabalhado durante a semana, em treinos e conversas "ao pé do ouvido", literalmente entra em campo. Os "ortopedistas do comportamento" podem agora seguir todas as reações do atleta no decorrer da partida. Reclamações, desobediências, desabafos, xingamentos, enfim, nada ficará impune. Conhecendo bem o perfil do atleta e seu padrão de comportamento, tornase possível até prever algumas de suas atitudes e antecipar-se a elas (substituindo um jogador irritado antes que ele seja expulso, por exemplo). 
O controle no estádio, já não acontece apenas no ambiente fechado, e no período de duração da partida. As fronteiras de espaço e de tempo de controle começam a se apagar. Os vinte e dois jogadores em campo, não são mais os únicos monitorados. Técnicos, jogadores reservas, árbitros, todos estão sujeitos a ter suas falas captadas pelas câmeras. Até o ex-jogador Pelé, que assistia da arquibancada a uma partida da copa, teve um de seus comentários "traduzidos" pelos especialistas em leitura labial da televisão.

Do mesmo modo, o controle não está restrito aos noventa minutos de um jogo. A exibição, no já citado quadro da TV, de uma conversa entre o técnico da seleção japonesa (o ex-jogador brasileiro Zico) e o atleta brasileiro Roberto Carlos, ainda no vestiário, bem antes da partida, mostra que não há mais lugar nem tempo externo a área de controle. Embora o estádio permaneça com seus limites físicos inalterados e o tempo de jogo continue o mesmo, gradativamente, os novos dispositivos de controle vão atravessando "todos os espaços e todos os tempos, engolindo o "fora"' (SIBILIA, 2002, p. 29).

Esses fragmentos não nos permitem dizer que o Estádio Panóptico deixou de existir, mas são pequenas pistas que nos sugerem que:

Há aqui uma modificação no sentido de vigilância, que passa da sociedade disciplinar à sociedade de controle. Na primeira, [...] o problema era o movimento físico dos indivíduos, seu deslocamento espacial. Vigiar era, basicamente, regular os passos das pessoas, era olhar. [...] [Na segunda], vigiar passou a significar, sobretudo, interceptar, ouvir, interpretar (COSTA, 2004, p. 164).

Se situarmos essas alterações nos estádios, junto com o fim do Passe, ${ }^{8}$ e o abrandamento das concentrações, notaremos aqui uma alteração gradual na lógica de poder. O surgimento de novos dispositivos de poder, cada vez mais sutis e menos evidentes, permite que o controle seja exercido de modo mais eficaz mesmo ao ar livre, dispensando os grandes meios de confinamentos que caracterizavam as sociedades disciplinares e o futebol moderno.

Todas essas mudanças, esse novo campo de saber-poder que se irrompe, não surgem desacompanhadas. Outra grande modificação surge com esse novo interesse pela fala dos atletas. 


\section{A VISIBILIDADE E A NOVA MORAL DO FUTEBOL}

Sobre isso, Nelson Rodrigues, um pouco antes da partida contra o Uruguai em 1959, escreveu sobre um dos personagens daquele episódio:

Contam que Almir xinga os adversários. Então pergunto: - Será o primeiro? Não me parece. O futebol jamais foi mudo, jamais exigiu do craque um silêncio de sarcófago. Direi mais, se me permitem: - o futebol é o mais falado e o mais pornográfico dos esportes. Durante os noventa minutos, tanto os craques em campo como o torcedor nas arquibancadas rugem os palavrões mais resplandecentes do idioma. Dirse-ia que tanto o público como o craque têm, no berro pornográfico, um estímulo vital, precioso e irresistível. E se o meu personagem xinga os adversários, não faz outra coisa senão insistir num hábito que data dos nautas camonianos. Repito: - o futebol se nutre de pornografia como uma planta de luz (RODRIGUES, 1993, p. 74).

As ofensas entre os jogadores nunca foram tratadas como um problema no futebol. Sempre se soube que os atletas tentavam intimidar ou desequilibrar emocionalmente o adversário, com provocações e xingamentos. Por que então Materazzi foi punido por xingar Zidane? Por que algo tão corriqueiro, de repente se torna um problema, que merece punição? A resposta para estas questões, assim como para a questão inicial de nosso texto, parece estar na visibilidade adquirida pelo esporte.

A gravidade de uma humilhação depende do público. Se os dois estivessem num terreno baldio, apenas assistidos por alguma cabra vadia, a coisa não teria nenhum patético. È a testemunha que valoriza e dramatiza as ofensas (RODRIGUES, 1993, p. 116).

Cada vez mais, o futebol vem se tornando um espetáculo para a televisão. Como em qualquer programa televisivo destinado ao entretenimento familiar, ofensas, agressões, palavrões, e qualquer atitude que possa servir de "mau exemplo", 9 não são bem-vindos. Se a busca pela audiência fez a TV dissecar a partida em seus mínimos detalhes, o controle sobre esses detalhes passa a ser desejável. Assim como o advento das sociedades industriais exigiu "uma formidável ofensiva da morali- 
zação sobre a população no século XIX" (FOUCAULT, 1979, p. 133), com a visibilidade proporcionada pelo aprimoramento das transmissões televisivas, uma nova moral passa a ser necessária.

Essa transformação é sentida na evolução da campanha da FIFA pelo Fair Play ("jogo limpo"). Se na sua gênese, no final dos anos 70, essa campanha se resumia em pregar a obediência voluntária às 17 regras do jogo, hoje ela é bem mais abrangente do que isso. Na tentativa de realizar uma reforma moral dos jogadores, afastando-os ao máximo daqueles que foram chamados de bárbaros por Oscar Wilde, ${ }^{10}$ o Fair Play se transformou em uma espécie de décima oitava regra, "não escrita", que pune de ofensas, principalmente aquelas de conteúdo racista, à falta de cordialidade, como não jogar a bola pra fora para que um adversário contundido receba atendimento.

Nesse novo modelo de conduta, até mesmo a dor do jogador passou a ser vigiada. Durante uma partida na copa de 2002, um jogador turco foi expulso por chutar a bola, com o lance já paralisado, sobre o meia brasileiro Rivaldo, que desmoronou com as mãos no rosto. Após a partida, Rivaldo também foi punido, por simular uma contusão mais grave do que realmente havia sido. A imagem havia mostrado que a bola não o acertou no rosto, e sim na perna.

Na moral do futebol contemporâneo, parece haver cada vez menos espaço para "Macunaímas".

\section{CONSIDERAÇÕES}

Minha vulgar e profunda devoção ao futebol não conhece limites. E como o futebol televisionado pode ser comparado ao fantástico impacto de assistir a um jogo no estádio? É como água destilada e Stolichnaya.

Dmitri Shostakovich

A maneira como vivenciamos o futebol atualmente, está tão impregnada pela imagem da televisão, que falas como a de Dmitri Shostakovich ou de Nelson Rodrigues nos soam como deliciosas insanidades. Nossa dependência da televisão chegou a ponto tal, que imensos telões começam a ser instalados em estádios, como se aquele jogo que acontece no gramado fosse incompleto, por não possuir replays, tira- 
teimas, closes, câmeras invertidas, entre outros recursos que nos acostumamos a ver.

Essa mudança em nosso olhar atingiu em cheio o futebol. Como a protagonista do filme de Jacques Audiard, ${ }^{11}$ passamos a ler lábios, e a exigir dos atletas e técnicos mais cuidados com as palavras. Passamos também a enxergar mais, e assim, qualquer tentativa de levar vantagem na partida, ludibriando ao árbitro com artimanhas ilegais, é facilmente desmascarada e condenada. $\mathrm{O}$ que antes parecia um genial passe de mágica, hoje soa como patético e fajuto truque. Uma nova moral, assim como novos mecanismos de controle, emerge da visibilidade proporcionada pela televisão.

Diante da progressiva instalação dessa nova lógica do poder, com dispositivos mais sutis e eficazes que os anteriores, o estádio contemporâneo já não parece o mesmo que foi estudado por Florenzano (1998). O próprio futebol também dá sinais de mudanças. "É claro que existe todo tipo de resquício de sociedade disciplinares, que persistirão por anos a fio, mas já sabemos que nossa vida se desenrola numa sociedade de outro tipo, que deveria chamar-se segundo o termo proposto por William Burroughs [...] de sociedade de controle" (Deleuze, 1999, p. 5). Uma análise mais completa, das transformações que vem sofrendo os outros mecanismos disciplinares descritos por Florenzano, seria esclarecedora. Mas isso já é assunto para outros artigos.

Por fim, creio que os caminhos da resistência a esses novos mecanismos de controle, não passam por atitudes saudosistas ou ludistas. Não se trata de regressar a uma situação passada, mas de buscar outras formas, sem controles nem disciplinas. Deleuze (1999) aponta a criação artística como o caminho para a resistência dentro de uma sociedade de controle. (Re)descobrir a arte que há no futebol contemporâneo pode não ser tarefa fácil, mas para aqueles que tantas vezes já decretaram sua morte definitiva, vale a pena lembrarmos uma frase dita pelo ex-presidente do Palmeiras, Mustafá Contursi:

- No futebol, as coisas definitivas nunca são definitivas.

\section{On my lips: visibility and control in contemporary football}

\section{ABSTRACT}

This article aims at analising how television and its permanent evolution has deeply altered football. Based on comparison of a few episodes, it tries to reflect on how 
growing visibility in the last 50 years has been altering the way football has been watched as well as its own dynamics.

KEYWORDS: football - panoptism - society of control

Sobre mis labios: visibilidad y controle en el fútbol contemporáneo

\section{RESUMEN}

Este artículo busca analizar como el adviento de la televisión, y su permanente evolución, provocó (y aún provoca) grandes cambios en el fútbol. Apoyado en la comparación de algunos episodios, busca reflexionar sobre cómo la creciente visibilidad viene cambiando, en esos últimos 50 años, no únicamente la manera como acompañamos este espectáculo, sino su propia dinámica.

PALABRAS-CLAVES: fútbol - panoptismo - sociedad de control

\section{NOTAS}

1 Refiro-me aqui à tese, bastante popular, de que o resultado da final da Copa da França (França 3 x 0 Brasil) teria sido previamente acertado entre as empresas Nike e Adidas.

2 Fédération Internationale de Football Association: a entidade máxima do futebol mundial.

3 A primeira transmissão brasileira foi em 1950. Em 1960, já havia pelo menos seis emissoras e cerca de 200 mil aparelhos receptores no Brasil (fonte: http://www.tudosobretv.com.br ).

4 O futebol esteve presente em momentos marcantes da TV brasileira, como na primeira transmissão externa direta, feita em 1955 (Santos x Palmeiras pela TV Record/SP) e na primeira transmissão interestadual em 1956, Brasil x Itália, direto do Maracanã para São Paulo, pela TV Tupi.

5 O lance pode ser visto em detalhes no filme oficial da copa de 94: Todos os corações do Mundo, de Murilo Salles.

6 A agressão, assim como ocorreu na copa de 94, não foi vista pelo árbitro principal, e sim foi denunciada a ele pelo quarto árbitro. Alguns rumores dão conta de que o quarto árbitro teria visto o replay do lance em monitores de TV junto ao campo, o que também seria inédito (já que o recurso do vídeo para sanar dúvidas da arbitragem não é permitido no futebol). Todavia, como essa informação é veementemente negada pela FIFA e pelos árbitros, preferimos desconsiderá-la. 
7 Cine-jornal das décadas de 1950 a 1980 . Famoso pela sua peculiar maneira de registrar jogos de futebol.

8 Mecanismo jurídico que prendia o atleta ao clube, foi extinto internacionalmente em 1995.

9 É interessante que Zidane, em sua primeira entrevista após o episódio, tenha pedido desculpa a todos os educadores pelo mau exemplo que deu às crianças.

10 Famoso escritor inglês do final do século XIX, disse certa vez: "Rúgbi é um jogo para bárbaros jogado por cavalheiros. Futebol é um jogo para cavalheiros jogado por bárbaros" (CURI, 2006, p. 57).

11 Sobre meus lábios, de Jacques Audiard (SUR mes lèvres, 2001).

\section{REFERÊNCIAS}

COSTA, R. Sociedade de Controle. São Paulo em Perspectiva, ano 18, n. 1, p. 161-167, 2004.

CURI, F. No campo das idéias. Futebol \& Linguagem. São Paulo: Segmento, 2006. p. 56-57.

DELEUZE, G. O ato de criação. Folha de São Paulo, São Paulo, 27 jun. 1999. Caderno Mais!. p. 4-5.

DIÁRIO DE NOTÍCIAS. Brasil dobrou a rebeldia uruguaia: 3x1. Rio de Janeiro, 27 mar. 1959. p. 12.

. Rasgamos a "carta de valiente" dos uruguaios. Rio de Janeiro, 29 mar. 1959. p. 3.

FLORENZANO, J. P. Afonsinho e Edmundo: a rebeldia no futebol brasileiro. São Paulo: Musa, 1998.

FOUCAULT, M. Microfísica do poder. 12. ed. Rio de Janeiro: Graal, 1979.

. Vigiar e punir: história da violência nas prisões. 15. ed. Petrópolis: Vozes, 1987.

GALEANO, E. Futebol ao sol e à sombra. 3. ed. Porto Alegre: L\&PM, 2004. 
KFOURI, J. Itetra!!!! Disponível em: <http://blogdojuca.blog.uol.com. br/arch2006-07-09_2006-07-15.html>. Acesso em: 10 ago. 2006.

RODRIGUES, N. À sombra das chuteiras imortais: crônicas de futebol. São Paulo: Companhia das Letras, 1993.

SIBILIA, P. O homem pós-orgânico: corpo, subjetividade e tecnologias digitais. Rio de Janeiro: Relume Dumará, 2002.

SUR mes lèvres. Jacques Audiard e Tonino Benacquista. Paris: Cinema Parisien Inc., 2001.

ZERO HORA. Saída pelos fundos. Porto Alegre, 10 jul. 2006. Jornal da Copa, p. 5.

Recebido: 29 de setembro de 2006

Aprovado: 9 novembro de 2006

Endereço para correspondência:

Renato Machado Saldanha

Rua Sebastião Leão ${ }^{\circ} 178$, apto. 101, Azenha

Porto Alegre - Rio Grande do Sul

CEP 90050-090

E-mail:vandruik@ig.com.br 